Introduction: The aim of this study is to evaluate the effects of physiotherapy in patients who underwent oncological treatment including spirometric indicators: FEV1, VC, FVC, PEF, FEV1/FVC, FEF25, FEF50, FEF75. Moreover, the possible influence of duration of physiotherapy on ventilation activity of lungs was assessed.

Material and methods: The study considered 91 women after breast cancer therapy qualified for outpatient physiotherapy. All patients underwent radiation therapy, and more than half of the women received concurrent chemotherapy. To assess rates of respiratory disorders, the patients were subjected to spirometric tests. The clinical status of examined subjects was also taken into account. Results: Statistical analysis showed that the duration of physiotherapy contributed to increased ventilation index FEV $1 \%$ - with each treatment day corresponding to an average of 1.8 units. In contrast, the involvement of lymph nodes radically reduced the level of PEF by as much as 64 units. The results of linear modelling provided evidence of statistically significant effects of chemotherapy on spirometric indicators. What is more, a statistically significant impact of time of rehabilitation on FEV1 increase was estimated.

Conclusions: Physiotherapy leads to improvement of lung functions in patients with breast cancer after oncological treatment; progress is more evident in patients with advanced cancer after radical treatment.

Key words: breast cancer, physiotherapy, dyspnoea.

Contemp Oncol (Pozn) 2019; 23 (1): 47-51 DOI: https://doi.org/10.5114/wo.2019.82929

\section{Evaluation of the effectiveness of physiotherapy in patients after oncological breast cancer treatment based on spirometric indicators}

\author{
Iwona Kulik-Parobczy
}

Institute of Physiotherapy, Faculty of Physical Education and Physiotherapy, Opole University of Technology, Opole, Poland

\section{Introduction}

Advances in early detection and improved treatment of breast cancer have resulted in increased chances of survival after diagnosis, resulting in a lot of women living with the consequences of cancer treatment [1]. The adverse side effects of chemotherapy treatment include, among others, pain, fatigue, cachexia (wasting syndrome), diminished strength and lung capacity, and reduced range of movement [2-5].

There is evidence that women successfully treated for breast cancer have ongoing morbidity with symptoms of dyspnoea, exercise intolerance (reduced exercise tolerance as measured by peak oxygen consumption), and reduced physical capacity [6-10]. Effort dyspnoea and exercise intolerance in breast cancer survivors are associated not only with increased ventilatory demand secondary to deconditioning, but also with reduced inspiratory capacity (IC) and inspiratory muscle weakness [11].

Currently, physiotherapy forms the main intervention technique applied in preventing these complications. Respiratory physiotherapy forms a core specialty within physiotherapy and plays a key role in treatment of patients with respiratory diseases $[12,13]$. A variety of interventions, including pulmonary rehabilitation, early mobilisation, and airway clearance techniques have demonstrated beneficial effects on symptoms associated with respiratory diseases. These include enhanced pain management, sputum clearance and cough efficacy, reduced dyspnoea, and improved physical fitness [12]. The aim of this study involved the evaluation of the effects of physiotherapy in patients following oncological treatment, in particular including determination of whether rehabilitation in patients resulted in improvement of spirometric indicators and decreased occurrence of respiratory disorders. The assessment of the effect of the duration of the intervention program on ventilation activity of lungs was also performed.

\section{Material and methods}

The research involved patients after breast cancer treatment qualified for outpatient physiotherapy at the Rehabilitation Unit at the Cancer Centre and Institute of Oncology in Gliwice in 2012-2013. In total 91 patients underwent rehabilitation. The characteristics of this group are summarised in Table 1.

It can be seen in Table 1 that following the classification of malignant tumours, the prevailing tumour types were $T=2$ and $N=1$. A vast majority of patients had an expression of oestrogen receptors (3) and reached menopause. All women were subjected to radiation therapy, and more than half underwent concurrent chemotherapy. Patients participated in rehabilitation were on average two and a half years after the completion of radiotherapy. On average, physiotherapy took approximately three weeks and it was 
Table 1. Selected characteristics of qualified rehabilitated patients

\begin{tabular}{|c|c|c|c|c|c|}
\hline Risk factor & Mean \pm SD (range) & & Median & & \\
\hline Age & $57.1 \pm 10.5(26-74)$ & & 59 & & \\
\hline Tumour size $\left(\mathrm{cm}^{3}\right)$ & $2.5 \pm 1.6(0.1-9)$ & & 2.0 & & \\
\hline BMI $\left(\mathrm{kg} / \mathrm{m}^{2}\right)$ & $27.3 \pm 4.9(14.5-43.3)$ & & 26.7 & & \\
\hline Time RT (days) & $36.4 \pm 5.7$ & & & & \\
\hline Risk factor & Fraction & & & & \\
\hline Degree $(T)$ & $(0)=0 \%$ & $(1)=40 \%$ & $(2)=43.5 \%$ & $(3)=10.6 \%$ & $(4)=5.9 \%$ \\
\hline Degree (N) & $(0)=21.4 \%$ & $(1)=78.6 \%$ & & & \\
\hline Oestrogen recept. stat. & $(0)=15.8 \%$ & $(1)=7.9 \%$ & $(2)=19.7 \%$ & (3) $=56.6 \%$ & \\
\hline Progestogen recept. stat. & $(0)=31.6 \%$ & $(1)=14.5 \%$ & $(2)=17.1 \%$ & $(3)=36.8 \%$ & \\
\hline HER recept. stat. & $(0)=51.4 \%$ & $(1)=21.6 \%$ & $(2)=14.9 \%$ & $(3)=12.2 \%$ & \\
\hline Menopause status & Perimenopause $=12.2 \%$ & Menopause $=87.8 \%$ & & & \\
\hline Type of surgery & Mastectomy $=82 \%$ & Breast conserving therapy $=18 \%$ & & & \\
\hline RT (dose) & $50 \mathrm{~Gy}=75 \%$ & 60 Gy and $\geq 25 \%$ & & & \\
\hline
\end{tabular}

Table 2. Results of Student's $t$-test for subgroups of patients

\begin{tabular}{|c|c|c|c|c|c|c|c|c|}
\hline \multirow{3}{*}{$\begin{array}{l}\text { Type of surgery } \\
\text { Rehabilitation } \\
\text { status }\end{array}$} & \multicolumn{4}{|c|}{ Breast conserving therapy } & \multicolumn{4}{|c|}{ Mastectomy } \\
\hline & \multirow{2}{*}{$\begin{array}{c}\text { Before } \\
\text { Mean } \pm \text { SD }\end{array}$} & \multicolumn{3}{|c|}{ After } & \multirow{2}{*}{$\begin{array}{c}\text { Before } \\
\text { Mean } \pm \text { SD }\end{array}$} & \multicolumn{3}{|c|}{ After } \\
\hline & & Mean \pm SD & $t$ statistic & $p$-value & & Mean \pm SD & $t$ statistic & $p$-value \\
\hline FEV1 (l) & $2.32 \pm 0.66$ & $2.51 \pm 0.51$ & -4.17 & 0.0024 & $2.24 \pm 0.42$ & $2.57 \pm 0.48$ & -7.10 & $<0.0001$ \\
\hline FEV1 (\%) & $96.63 \pm 23.10$ & $105.60 \pm 23.58$ & -4.01 & 0.0031 & $97.74 \pm 21.48$ & $112.19 \pm 24.29$ & -5.91 & $<0.0001$ \\
\hline FVC (I) & $3.05 \pm 0.90$ & $3.03 \pm 0.51$ & -1.21 & 0.2584 & $2.99 \pm 0.52$ & $3.09 \pm 0.51$ & -2.62 & 0.0107 \\
\hline FVC (\%) & $106.75 \pm 28.13$ & $107.50 \pm 22.67$ & -1.31 & 0.2223 & $108.74 \pm 20.92$ & $112.16 \pm 22.82$ & -1.53 & 0.1309 \\
\hline PEF (I/min) & $341.81 \pm 101.96$ & $336.10 \pm 87.23$ & -0.49 & 0.6381 & $321.60 \pm 69.17$ & $348.96 \pm 62.06$ & -3.57 & 0.0007 \\
\hline PEF (\%) & $90.56 \pm 23.87$ & $90.20 \pm 22.68$ & -0.44 & 0.6695 & $87.88 \pm 20.86$ & $95.48 \pm 18.44$ & -3.44 & 0.0010 \\
\hline FEV1/FVC (\%) & $77.63 \pm 11.24$ & $82.30 \pm 8.96$ & -1.16 & 0.2745 & $75.12 \pm 8.67$ & $81.65 \pm 12.93$ & -3.43 & 0.0010 \\
\hline FEF25 (I/s) & $4.65 \pm 1.98$ & $4.81 \pm 1.25$ & -0.79 & 0.4479 & $4.44 \pm 1.18$ & $4.75 \pm 1.05$ & -2.26 & 0.0269 \\
\hline FEF25 (\%) & $82.63 \pm 32.55$ & $87.40 \pm 21.30$ & -0.79 & 0.4487 & $81.82 \pm 23.02$ & $87.67 \pm 19.97$ & -2.10 & 0.0395 \\
\hline FEF50 (I/s) & $2.67 \pm 0.93$ & $2.95 \pm 0.93$ & -2.35 & 0.0434 & $2.35 \pm 0.93$ & $3.07 \pm 0.98$ & -5.92 & $<0.0001$ \\
\hline FEF50 (\%) & $71.38 \pm 21.98$ & $79.70 \pm 24.81$ & -2.30 & 0.0467 & $63.52 \pm 27.24$ & $82.65 \pm 24.82$ & -5.57 & $<0.0001$ \\
\hline FEF75 (I/s) & $0.90 \pm 0.46$ & $1.26 \pm 0.68$ & -1.75 & 0.1138 & $1.76 \pm 8.58$ & $1.38 \pm 0.78$ & 0.42 & 0.6736 \\
\hline FEF75 (\%) & $66.63 \pm 30.90$ & $93.90 \pm 50.44$ & -1.75 & 0.1147 & $58.81 \pm 35.73$ & $105.52 \pm 61.83$ & -5.97 & $<0.0001$ \\
\hline
\end{tabular}

FEV1 - forced expiratory volume in one second, FVC - forced vital capacity, PEF - peak expiratory flow, FEV1/FVC - ratio of forced expiratory volume in one second to forced vital capacity, FEF-forced expiratory flow

performed following the physiotherapy treatment. The respiratory disorders in patients were assessed based on the spirometric tests including the following air flow indicators: forced expiratory volume in one second (FEV1), vital capacity (VC), forced vital capacity (FVC), peak expiratory flow (PEF), ratio of forced expiratory volume in one second to forced vital capacity (FEV1/FVC), and forced expiratory flow (FEF). The resulting material was used for statistical analysis.

\section{Statistical analysis}

Student's t-test for dependent observations for time intervals (preceding and following rehabilitation) was applied in the study. The assessment of the examined clinical factors on ventilation indicators relied on a linear model, which determines the relation between the dependent variable $Y$ and the set of predicting factors $X$ in the following form: $Y=b_{0}+b_{1} X_{1}+b_{2} X_{2}+\ldots+b_{k} X_{k}$.

In this equation $b_{0}$ is an intercept, and $b_{i}$ represents the regression coefficients (slopes) for explanatory variables (from 1 to $\mathrm{k}$ ). In the statistical analysis, only univariate and bivariate regressions were considered.

\section{Results}

The study involved the use of Student's t-test to compare the results before and after rehabilitation with regard to patients subjected to breast-conserving treatment and those after mastectomy.

Based on the results reported in Table 2, statistically significant differences in means of spirometric indicators before and after rehabilitation were estimated, especially in patients who underwent mastectomy. Linear univariate models of statisti- 
Table 3. Linear model of changes in lung ventilation indicators in patients without combined chemotherapy

\begin{tabular}{|c|c|c|c|c|c|}
\hline Response variable & Risk factor & Regression coefficient & Mean & Standard error & $p$-value \\
\hline FEV1 (\%) - after rehabilitation & Time of rehabilitation (days) & $\begin{array}{l}\text { Intercept } \\
\text { Slope }\end{array}$ & $\begin{array}{c}-23.22 \\
1.80\end{array}$ & $\begin{array}{c}10.78 \\
0.50\end{array}$ & $\begin{array}{l}0.0345 \\
0.0006\end{array}$ \\
\hline FVC (I) - after rehabilitation & Number of births & $\begin{array}{l}\text { Intercept } \\
\text { Slope }\end{array}$ & $\begin{array}{c}0.26 \\
-0.08\end{array}$ & $\begin{array}{l}0.08 \\
0.04\end{array}$ & $\begin{array}{l}0.0009 \\
0.0340\end{array}$ \\
\hline PEF (I/min) - after rehabilitation & Status of lymph nodes & $\begin{array}{l}\text { Intercept } \\
\text { Slope }\end{array}$ & $\begin{array}{c}83.14 \\
-63.78\end{array}$ & $\begin{array}{l}23.31 \\
24.41\end{array}$ & $\begin{array}{l}0.0006 \\
0.0108\end{array}$ \\
\hline PEF (I/min) - after rehabilitation & Tumour size $\left(\mathrm{cm}^{3}\right)$ & $\begin{array}{l}\text { Intercept } \\
\text { Slope }\end{array}$ & $\begin{array}{c}57.05 \\
-12.48\end{array}$ & $\begin{array}{c}13.53 \\
4.68\end{array}$ & $\begin{array}{l}0.0001 \\
0.0094\end{array}$ \\
\hline PEF (\%) - after rehabilitation & Status of lymph nodes & $\begin{array}{l}\text { Intercept } \\
\text { Slope }\end{array}$ & $\begin{array}{c}19.14 \\
-13.71\end{array}$ & $\begin{array}{l}6.55 \\
6.86\end{array}$ & $\begin{array}{l}0.0046 \\
0.0492\end{array}$ \\
\hline PEF (\%) - after rehabilitation & Tumour size $\left(\mathrm{cm}^{3}\right)$ & $\begin{array}{l}\text { Intercept } \\
\text { Slope }\end{array}$ & $\begin{array}{r}15.88 \\
-3.59\end{array}$ & $\begin{array}{l}3.73 \\
1.29\end{array}$ & $\begin{array}{c}0.0001 \\
0.006\end{array}$ \\
\hline FEV1/FVC (\%) - after rehabilitation & Time of rehabilitation (days) & $\begin{array}{l}\text { Intercept } \\
\text { Slope }\end{array}$ & $\begin{array}{c}-21.90 \\
1.48\end{array}$ & $\begin{array}{l}8.86 \\
0.41\end{array}$ & $\begin{array}{l}0.0158 \\
0.0006\end{array}$ \\
\hline FEF25 (I/s) - after rehabilitation & T degree & $\begin{array}{l}\text { Intercept } \\
\text { Slope }\end{array}$ & $\begin{array}{c}0.96 \\
-0.36\end{array}$ & $\begin{array}{l}0.32 \\
0.16\end{array}$ & $\begin{array}{l}0.0036 \\
0.0295\end{array}$ \\
\hline FEF25 (I/s) - after rehabilitation & Tumour size $\left(\mathrm{cm}^{3}\right)$ & $\begin{array}{l}\text { Intercept } \\
\text { Slope }\end{array}$ & $\begin{array}{c}0.91 \\
-0.23\end{array}$ & $\begin{array}{l}0.25 \\
0.09\end{array}$ & $\begin{array}{l}0.0004 \\
0.0078\end{array}$ \\
\hline
\end{tabular}

FEV1 - forced expiratory volume in one second, FVC - forced vital capacity, PEF - peak expiratory flow, FEV1/FVC - ratio of forced expiratory volume in one second to forced vital capacity, FEF-forced expiratory flow

Table 4. Linear univariate models of spirometric indicators in patients with concurrent chemotherapy

\begin{tabular}{|c|c|c|c|c|}
\hline Response variables & Regression coefficient & Mean & Standard error & $p$-value \\
\hline FEV1 (I) before rehabilitation & $\begin{array}{l}\text { Intercept } \\
\text { Slope }\end{array}$ & $\begin{array}{l}2.134 \\
0.234\end{array}$ & $\begin{array}{l}0.073 \\
0.097\end{array}$ & $\begin{array}{c}<0.0001 \\
0.0184\end{array}$ \\
\hline FVC (I) before rehabilitation & $\begin{array}{l}\text { Intercept } \\
\text { Slope }\end{array}$ & $\begin{array}{l}2.856 \\
0.263\end{array}$ & $\begin{array}{l}0.092 \\
0.123\end{array}$ & $\begin{array}{c}<0.0001 \\
0.0353\end{array}$ \\
\hline PEF (I/min) before rehabilitation & $\begin{array}{l}\text { Intercept } \\
\text { Slope }\end{array}$ & $\begin{array}{c}306 \\
37.31\end{array}$ & $\begin{array}{l}11.66 \\
15.58\end{array}$ & $\begin{array}{c}<0.0001 \\
0.0187\end{array}$ \\
\hline FEF25 (I/s) before rehabilitation & $\begin{array}{l}\text { Intercept } \\
\text { Slope }\end{array}$ & $\begin{array}{l}4.137 \\
0.647\end{array}$ & $\begin{array}{l}0.207 \\
0.277\end{array}$ & $\begin{array}{c}<0.0001 \\
0.0217\end{array}$ \\
\hline FEV1 (I) after rehabilitation & $\begin{array}{l}\text { Intercept } \\
\text { Slope }\end{array}$ & $\begin{array}{l}2.402 \\
0.282\end{array}$ & $\begin{array}{l}0.082 \\
0.107\end{array}$ & $\begin{array}{c}<0.0001 \\
0.0099\end{array}$ \\
\hline FVC (I) after rehabilitation & $\begin{array}{l}\text { Intercept } \\
\text { Slope }\end{array}$ & $\begin{array}{l}2.905 \\
0.333\end{array}$ & $\begin{array}{l}0.087 \\
0.114\end{array}$ & $\begin{array}{c}<0.0001 \\
0.0044\end{array}$ \\
\hline Age of lungs after rehabilitation & $\begin{array}{l}\text { Intercept } \\
\text { Slope }\end{array}$ & $\begin{array}{c}55.29 \\
-8.461\end{array}$ & $\begin{array}{l}2.941 \\
3.789\end{array}$ & $\begin{array}{c}<0.0001 \\
0.0285\end{array}$ \\
\hline
\end{tabular}

FEV1 - forced expiratory volume in one second, FVC - forced vital capacity, PEF - peak expiratory flow, FEF-forced expiratory flow

Table 5. Linear bivariate regression of forced expiratory volume in one second (FEV1) on interval since oncological treatment and time of rehabilitation

$\begin{array}{lccccc}\text { Response variable } & \text { Risk factor } & \text { Regression coefficient } & \text { Mean } & 95 \% \text { Cl } & p \text {-value } \\ \text { FEV1 (I) before - after rehabilitation } & \text { Intercept } & -0.198 & (-0.497,0.091) & 0.0831 \\ & \text { Start rehabilitation - end RT (months) } & \text { Slope } & 0.003 & (0.001,0.005) & 0.0044 \\ & \text { Time of rehabilitation (days) } & \text { Slope } & 0.021 & (0.008,0.036) & 0.0038\end{array}$

cally significant effects of spirometric indicators and selected clinical factors on ventilation of lungs are reported in Table 3.

The data in Table 3 show that the time of physiotherapy significantly contributed to an increase in FEV1\% - approximately 1.8 units per day of rehabilitation. In contrast, lymph node status radically reduced the level of PEF by as much as 64 units. The statistically significant linear models of a possible effect of chemotherapy on lung ventilation indicators are given in Table 4.
The results in Table 4 demonstrate the positive influence of chemotherapy on the analysed spirometric indicators before and after rehabilitation. The effect of rehabilitation on FEV1 was also estimated in a linear bivariate regression approach (Table 5 ).

The results reported in Table 5 provide evidence of a statistically significant increase in FEV1 in patients since the end of oncological treatment (approximately 0.04 I per year of the interval). What is more, a week of rehabilitation 


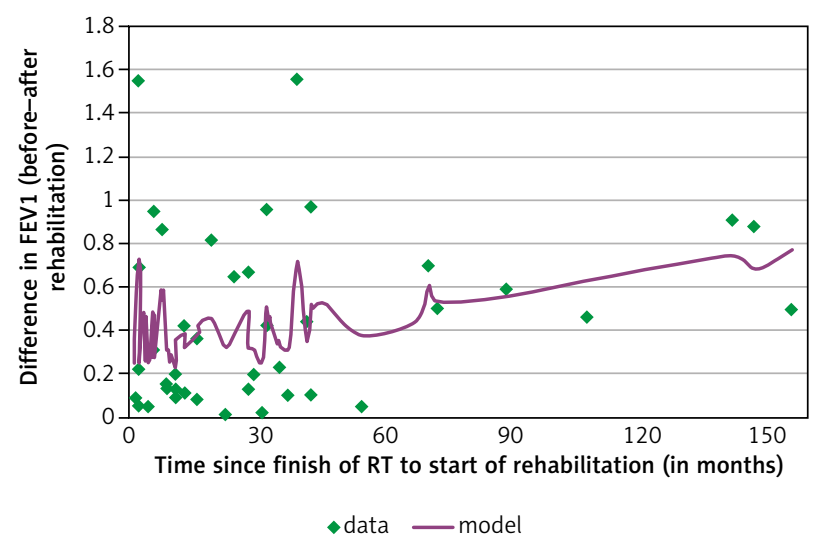

Fig. 1. Forced expiratory volume in one second (FEV1) increase vs. interval since the end of oncological treatment

is equivalent to half a year of the non-intervention recovery of lungs in women. These results demonstrate a significant impact of the rehabilitation on FEV1. The described model is presented graphically in Figure 1 and 2.

\section{Discussion}

Based on the obtained results, a possible impact of the physiotherapeutic program on the progress in spirometric functions in breast cancer patients can be established. However, overall health development was considerably stronger in radically treated women than in women who underwent breast-conserving therapy. It seems that the better rehabilitation effect is observed in radical treatment leading to a more intensive regeneration of lungs.

The estimated correlations between differences in spirometric indicators before and after rehabilitation were mainly attributable to clinical factors, i.e. tumour size and lymph node status (Table 1). This could be explained by the intensity of the conducted radiotherapy, which in turn is related to radiation injury of lungs and their stronger recovery. Similar conclusions were reached in a study [14] on FVC, FEV1, carbon monoxide in patients suffering from irradiation after breast cancer therapy. In the cited study, the spirometric tests deteriorated relatively over the period of six months following radiotherapy and returned to a level similar to the one recorded before irradiation one year after the end of observation [14].

Contrasting observations to the present study of the effect of chemotherapy with concurrent radiotherapy on the spirometric measures were found in [15]; however, they are in accordance with [16]. The latter can be explained by stronger cell regeneration and reconstruction of lung functions in patients with the more intensive medical intervention [17].

Statistical correlations were also estimated as regards spirometric efficiency with an interval since the end of oncological treatment and time of rehabilitation. These findings can be interpreted by the natural regeneration of lungs since the end of oncological treatment. However, noteworthy is the fact that a week of rehabilitation is an equivalent to half a year of the non-intervention recovery of lungs in women. This result shows significant power of the rehabilitation on lung functions after breast cancer radiotherapy.

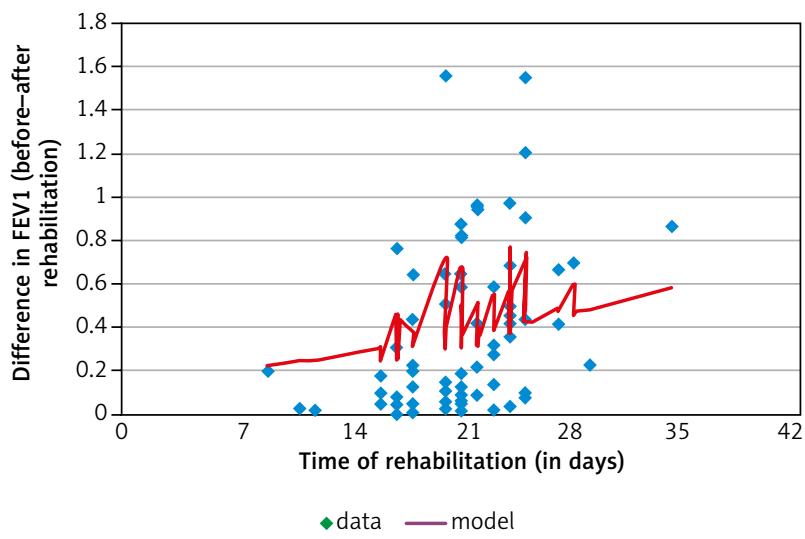

Fig. 2. Forced expiratory volume in one second (FEV1) increase vs. time of rehabilitation

Based on the collected material, applied methodology, and obtained statistical results, positive physiotherapeutic effects on breast cancer patients can be established. The presented findings are not alone. Similar results were previously reported in the scientific literature worldwide [18-24]. They confirm the statement regarding the positive impact of rehabilitation on the condition of oncologically treated patients.

\section{Conclusions}

Physiotherapy leads to the improvement of lung function in patients with breast cancer following oncological treatment; progress is particularly evident in patients in more advanced cancer stages.

Clinical factors such as age of patients, body mass index, tumour size, nodal status, or menopause had no statistical effect on spirometry of lungs.

Time of physiotherapy played an important role in basic lung functions in breast cancer patients.

The author declares no conflict of interest.

\section{References}

1. Cancer Research UK. Breast Cancer Survival Statistics cited 2014 Available from: http://www.cancerresearchuk.org/.

2. Cantarero-Villanueva I, Fernández-Lao C, Fernández-de-Las-Peñas C, López-Barajas IB, Del-Moral-Ávila R, de la-Llave-Rincón Al, ArroyoMorales M. Effectiveness of water physical therapy on pain, pressure pain sensitivity and myofascial trigger points in breast Cancer survivors: a randomized, controlled clinical trial. Pain Med 2012; 13: 1509-1519.

3. Hayes SC, Rye S, Disipio T, et al. Exercise for health: a randomized, controlled trial evaluating the impact of a pragmatic, translational exercise intervention on the quality of life, function and treatment-related side effects following breast cancer. Breast Cancer Res Treat 2013; 137: 175-186.

4. Lee SA, Kang J, Kim YD, An AR, Kim SW, Kim YS, Lim JY. Effects of a scapula-oriented shoulder exercise programme on upper limb dysfunction in breast cancer survivors: a randomized controlled pilot trial. Clin Rehabil 2010; 24: 600-613.

5. Santos ALB, Marinho RC, Lima PNM, Fortes RC. Subjective nutritional assessment proposed by the patient versus other methods of evaluating nutritional status in cancer patients. Rev Bras Nutr Clin 2012; 27: 243-249. 
6. Yee J, Davis GM, Beith JM, et al. Physical activity and fitness in women with metastatic breast cancer. J Cancer Surviv 2014; 8: 647-656.

7. Burnett D, Kluding P, Porter C, Fabian C, Klemp J. Cardiorespiratory fitness in breast cancer survivors. Springerplus 2013; 2: 68.

8. Smoot B, Johnson M, Duda J, Krasnoff J, Dodd M. Cardiorespiratory fitness in women with and without lymphedema following breast cancer treatment. Cancer Clin Oncol 2012; 1: 21-31.

9. Jones W, Courneya S, Mackey R, et al. Cardiopulmonary function and age-related decline across the breast cancer survivorship continuum. J Clin Oncol 2012; 30: 2530-2537.

10. Travers J, Dudgeon DJ, Amjadi K, et al. Mechanisms of exertional dyspnea in patients with cancer. J Appl Physiol 2008; 104: 57-66.

11. O'Donnell DE, Webb KA, Langer D, Elbehairy AF, Neder JA, Dud geon DJ. Respiratory Factors Contributing to Exercise Intolerance in Breast Cancer Survivors: A Case-Control Study. J Pain Symptom Manag 2016; 52: 54-63.

12. Bott J, Blumenthal S, Buxton M, et al. Guidelines for the physiotherapy management of the adult, medical, spontaneously breathing patient. Thorax 2009; 64 (Suppl 1): i1-51.

13. Stiller K. Physiotherapy in intensive care: An updated systematic review. Chest 2013; 144: 825-847.

14. Jaen J, Vazquez G, Alonso E, León A, Guerrero R, Almansa JF. Changes in pulmonary function after incidental lung irradiation for breast cancer: A prospective study. Int J Radiat Oncol Biol Phys 2006; 65: 1381-1388.

15. Spyropoulou D, Leotsinidis M, Tsiamita M, Spiropoulos K, Karda makis D. Pulmonary function testing in women breast cancer treated with radiotherapy and chemotherapy. In Vivo 2009; 23: 867-871.

16. Miglani A, Arora R. The effect of chemotherapy on the pulmonary function tests in cancer patients with healthy lungs. J Clin Diagn Res 2011; 5: 798-800.

17. Courneya K, Mackey J, Bell GJ, Jones LW, Field CJ, Fairey AS. Randomized controlled trial of exercise training in postmenopausa breast cancer survivors: cardiopulmonary and quality of life outcomes. J Clin Oncol 2003; 21: 1660-1668.

18. Untch M, Ditsch N, Hermelink K. Immunotherapy: new options in breast cancer treatment. Expert Rev Anticancer Ther 2003; 3: 403 408.

19. Woźniewski M. Rehabilitacja w onkologii. In: Rehabilitacja medy czna, Kwolek A (ed.). Urban \& Partner, Wrocław 2003; 592-619.

20. Basen-Engquist K, Taylor C, Rosenblum C, et al. Randomized pilot test of a lifestyle physical activity intervention for breast cancer survivors. Patient Educ Couns 2006; 64: 225-234.

21. Irwin M, Smith A, Mc Tiernan A, et al. Influence of pre-and postdiagnosis physical activity on mortality in breast cancer survivors: the health, eating, activity, and lifestyle study. J Clin Oncol 2008; 26: 3958-3964.

22. Matthews C, Wilcox S, Hanby CL, Der Ananian C, Heiney SP, Gebretsadik T, Shintani A. Evaluation of a 12-week home-based walking intervention for breast cancer survivors. Support Care Cancer 2007; 15: 203-211.

23. Mefferd K, Nichols J, Pakiz B. A cognitive behavioral therapy intervention to promote weight loss improves body composition and blood lipid profiles among overweight breast cancer survivors. Breast Cancer Res Treat 2007; 104: 145-152.

24. Pinto B, Frierson G, Rabin C, Trunzo JJ, Marcus BH. Homebased physical activity intervention for breast cancer patients. J Clin Oncol 2005; 23: 3577-3587.

\section{Address for correspondence}

\section{wona Kulik-Parobczy}

Institute of Physiotherapy

Faculty of Physical Education and Physiotherapy

Opole University of Technology

76 Prószkowska St.

45-758 Opole, Poland

e-mail: i.kulik@poczta.onet.pl

Submitted: 4.12 .2018

Accepted: 7.01 .2019 